\title{
Fact or fiction: the truth behind the doctors company claims regarding licit and illicit opioids
}

This article was published in the following Dove Press journal: Journal of Pain Research

\author{
Lisa Lynn Dragic' \\ Jeffrey Fudin ${ }^{2-5}$ \\ Michael E Schatman ${ }^{6,7}$ \\ 'Department of Pharmacy, Central \\ Arkansas Veterans Healthcare System, \\ Little Rock, AR, USA; '2Department of \\ Pharmacy, Albany Stratton VA Medical \\ Center, Albany, NY, USA; ${ }^{3}$ Remitigate, \\ LLC, Delmar, NY, USA; ${ }^{4}$ Albany \\ College of Pharmacy and Health \\ Sciences, Albany, NY, USA; ${ }^{5}$ Western \\ New England University College \\ of Pharmacy, Springfield, MA, USA; \\ ${ }^{6}$ Research and Network Development, \\ Boston Pain Care, Waltham, MA, USA; \\ ${ }^{7}$ Department of Public Health and \\ Community Medicine, Tufts University \\ School of Medicine, Boston, MA, USA
}

Correspondence: Micahel E Schatman Public Health and Community Medicine, Tufts University School of Medicine, Boston, MA, USA

Email michael.schatman@tufts.edu
Over 35 years ago, California was in the midst of a medical malpractice insurance crisis. Malpractice lawsuits and jury awards hit an all-time high, causing insurance companies to raise their rates by more than $300 \% .{ }^{1}$ This crisis brought leading physicians together, which led to the passage of Medical Injury Compensation Reform Act (MICRA). ${ }^{1}$ The physicians recognized the need to continue to advocate and protect physicians, and thus, The Doctors Company was formed. ${ }^{1}$

The Doctors Company changed the landscape of the insurance world, as they became the first insurance carrier to be founded and led by physicians. ${ }^{1}$ As physicians led the company, the founders felt confident that they could focus on member needs rather than answering the demands of stockholders. Likewise, they believed that the company would be aligned with physicians' interests and in an ideal position to represent and advocate for physicians in political and legal settings. ${ }^{1}$ According to the website, "The mission was clear: The Doctors Company would work relentlessly to advance, protect, and reward the practice of good medicine." Does their message and vision still hold true today in a profit-driven health system?

During the second quarter of 2017, the company's publication, Doctor's Advocate, released an article by Howard Marcus, MD: "Prescribing Opioids Safely."2 Given the title, one would imagine that this article would educate its readers on safe opioid prescribing and risk mitigation strategies. However, this article offers very little insight for clinicians into safe opioid prescribing and appears to merely be filled with misleading "alternative facts" correlated with non-scientifically based rhetoric that has been ubiquitous among mainstream media sources and political "bully pulpits."' Compassionate clinicians should take pause to assess whether the author and The Doctors Company have wandered astray from the group's initial mission, askew from their pledge to instead relentlessly advance, protect, and reward politicians and lawmakers inapposite to the Hippocratic Oath. While we certainly acknowledge the inherent dangers of prescription opioids, we also know that in appropriate patients they can be effective and preserve the will to live, lest we remember those patients who have taken their own lives due to undertreated intractable pain. According to the oath, a physician pledges to "...remember that I remain a member of society, with special obligations to all my fellow human beings, those sound of mind and body as well as the infirm." Accordingly, casting aside these obligations by focusing on the removal of access to opioids when indicated is a serious breach of professional obligation. 


\section{Facts or fake medical news?}

The writer and educator, William Zinsser wrote, "The most important sentence in any article is the first one. If it doesn't induce the reader to proceed to the second sentence, your article is dead."3 Marcus perhaps took this to heart, captivating readers by having them consider a number of rather hyperbolic "facts". Given the lack of citations and explanation surrounding these so-called truths, we highlight key issues to enlighten those that choose the path of informed decision.

Consider these facts:

1. The US consumes $99 \%$ of the world's hydrocodone.

- The US uses hydrocodone (which milligram for milligram is presumed to be roughly equivalent to oral morphine) in combined formulations with acetaminophen, aspirin, ibuprofen, and in cold products with atropine and related alkaloids. Outside North America, dihydrocodeine, a codeine derivative and weaker analgesic compared to hydrocodone, and simply morphine itself are the drugs more commonly used for relief of mild to moderate pain. ${ }^{4}$ Hydrocodone is marketed in Canada only in cough syrups or elixirs but is not otherwise used for pain treatment. ${ }^{4}$ Hydrocodone has also been used in Australia but has largely been replaced by morphine. ${ }^{4}$ Ignoring this exclusiveness of hydrocodone skews explanations of why the US consumes the worldwide majority of hydrocodone and the reasons why hydrocodone was once prescribed more than any other medication in the US. The practical reality is that hydrocodone became preferred by physicians and other prescribers nationwide because it was the only opioid analgesic of significant potency that for many years was not a schedule II controlled substance per United States Federal Regulations. ${ }^{5,6}$ During that time span, hydrocodone combination products were classified as schedule III controlled substances, as it was originally believed that the combinations with acetaminophen, aspirin, ibuprofen, and/or atropine alkaloids were less abusable compared to other products and, with the exception of the latter, potentially more effective in treating pain. ${ }^{5,6}$ This meant that prescribers could write prescriptions for hydrocodone with up to five refills and avoid multiple patient visits for prescription renewals, which are required of oxycodone and nearly all other chronic opioid analgesics. ${ }^{5,6}$

2. The number of annual opioid prescriptions written in the US is roughly equal to the number of adults in the country.

- This statement is an example of a spurious correlation that is shamefully aligned with the agenda-driven rheto- ric spewed by politicians and nonscientists. To highlight the inanity, consider the congruent correlations between the cost of bananas vs opioid deaths, points scored by losing Super Bowl team vs opioid deaths, or the cost of 16-ounces of potato chips vs opioid deaths, all of which are more closely parallel than opioid prescriptions written vs number of adults in the US. ${ }^{7}$

- According to the Morbidity and Mortality Weekly Report on Changes in Opioid Prescribing in the US, the amount of opioids prescribed peaked in 2010 and has subsequently decreased each year through $2016 .{ }^{8}$ More specifically between 2006 and 2016, the annual prescribing rate decreased from 0.724 opioid prescriptions per person to 0.665 prescriptions per person for all opioids, which calculates to an $8.1 \%$ reduction in opioid prescriptions written overall. ${ }^{9}$ When considering the data from 2006 through 2016 for high-dose opioid prescribing, which was defined as a total daily dosage of $\geq 90$ MME, there was a substantial $46.8 \%$ overall reduction during that 10-year span. ${ }^{9}$ These data were obtained from QuintilesIMS Transactional Data Warehouse, representing 59,000 pharmacies ( $88 \%$ of the prescriptions) across the US. This type of data collection poses several limitations. ${ }^{9}$ First, the QuintilesIMS estimates have not been validated. Second, the analysis does not include clinical outcomes. Lastly, the data obtained did not include the indications for which opioids were prescribed. Thus, one cannot assess the appropriateness of these medications and the setting in which they were prescribed - acute, chronic, palliative care, or end-of-life care.

- What exactly does "roughly equal" mean and is this in fact true? Taking a look at the data reported by the CDC's 2017 Annual Surveillance Report (Table 1), from 2012 to 2016 , there was a steady decline in the amount of opioid prescriptions written. Furthermore, from 2014 to 2016, the number of adults exceeded the annual number of opioid prescriptions written.

3. Nine million Americans take prescribed opioids on a long-term basis.

- From where Dr. Marcus obtained this figure is unclear. The latest data that we could find suggest that there were actually 13 million Americans prescribed opioids as longterm opioid therapy (LTOT) in 2013-2014. ${ }^{10}$ However, given the steady annual decreases in the number of opioids prescribed since 2014, we suspect that this number has likely decreased. Irrespective of the actual number and Marcus's source, we are confident that he presented the number as a means of alarming his readers. If 9 million 
Table I Opioid prescribing rates in adult population aged 18 years and older

\begin{tabular}{llllll}
\hline Data type & $\mathbf{2 0 1 2}$ & $\mathbf{2 0 1 3}$ & $\mathbf{2 0 1 4}$ & $\mathbf{2 0 1 5}$ & $\mathbf{2 0 1 6}$ \\
\hline Number of adults & $240,291,024$ & $242,625,484$ & $244,986,302$ & $247,279,859$ & $249,485,228$ \\
Annual number of opioid prescriptions written (million) & 254 & 246 & 240 & 226 & 214 \\
Opioid prescribing rate (per 100 persons) & 81.3 & 78.1 & 75.6 & 70.6 & 66.5 \\
Total population & $313,998,379$ & $316,204,908$ & $318,563,456$ & $320,896,618$ & $323,127,513$ \\
\hline
\end{tabular}

Note: Data from Centers for Disease Control and Prevention. Annual Surveillance Report of Drug-Related Risks and Outcomes - United States, 20I 7. Surveillance Special Report I. Centers for Disease Control and Prevention, U.S. Department of Health and Human Services; 2017. Available from: https://www.cdc.gov/drugoverdose/pdf/pubs/20I7-cdcdrug-surveillance-report.pdf. ${ }^{9}$

is an accurate figure, is it not tragic that fewer than $10 \%$ of the 100 million suffering from chronic pain are able to access opioid analgesia on an ongoing basis, and overall deaths attributable to such a large number of prescribed opioids are therefore quite low? ${ }^{11}$

4. Nearly $60 \%$ of Americans have leftover opioids in their homes, and $20 \%$ have shared their opioids with others, often to help with pain management.

- Hendricks et al conducted a national survey among US adults with recent opioid medication use to examine the pervasiveness of sharing opioid medications, medication storage and disposal practices, and the sources of information received. ${ }^{12}$ Of the 4,836 that were sampled, 1,055 were eligible based on the past year opioid use, and of that group, 1,032 completed the survey. It is important to note that the survey was conducted from February 24 to March 16, 2015. Given the short time frame and lack of US census data on how many adults used prescription opioids within the past year, the results of this study cannot be extrapolated, and that this study sample represents all US adults cannot be verified. Frequently, agenda-driven medical writers jump to extremely inaccurate conclusions and focus on the negative aspects that a study may have revealed.

- If we look at these data from an alternative perspective, of the $20.7 \%$ (weighted percentage) who reported sharing opioid medications with another person, the primary reason for $73 \%$ of them was to help someone else manage his or her pain. ${ }^{12}$ Perhaps we are missing the bigger picture, with uncontrolled pain remaining a major issue. This survey sheds some positive light on the situation, including that only $1 \%$ of respondents no longer using opioid medications reported they would sell them. Dr. Marcus did not share this important information.

5. In 2015, 19,000 Americans died of an opioid overdose, and the death rate from all opioids (including heroin) now exceeds the death rate from motor vehicle accidents.

- When contemplating these statistics, the important question to consider is whether the opioids are licit or illicit.
In a 2017 article, the authors used the Department of Justice data from a state that breaks down deaths as caused by a licit vs illicit opioids, concluding that as many as $85 \%$ of overdose deaths that the CDC has attributed to "prescription opioids" were actually due to illicit fentanyl and its analogs and/or heroin. ${ }^{13}$ Although the media and policy makers continue to pay insufficient attention to this distinction, doing so is disingenuous - as is citing such blatantly dishonest figures. Similarly, The Hill recently released an article regarding DEA to Target Pharmacies, Prescribers in Crackdown in which the authors stated, "at least 66,000 deaths from overdoses reported, including 42,249 deaths from opioids." ${ }^{14}$ This statistic fails to inform the reader of what percentage of opioid deaths were due to illegally obtained prescription vs nonprescription opioids. Finally, Somerville et al examined fentanyl deaths in Massachusetts over a 6-month period from 2014 to 2015 , finding that $82 \%$ of the fentanyl deaths were likely due to illicitly manufactured fentanyl, with only $4 \%$ attributed to legal, pharmaceutical fentanyl. ${ }^{15}$ Polypharmacy also plays a significant role in opioid overdoses. The authors of a 2016 study found that of over 2 million patients who were prescribed opioid analgesics, $80 \%$ also were prescribed a benzodiazepine. ${ }^{16}$ There were 629 deaths involving opioid analgesics in the study, and alcohol was involved in $12.2 \%$ of the fatal overdoses involving opioid analgesics. ${ }^{16}$ Most recently, Hannah et al found an average of six potentially deadly substances in toxicologies of supposed "prescription opioid overdose decidents.." ${ }^{17}$ Dr. Marcus's cited statistics regarding opioid overdoses and mortalities are oversimplified and clearly do not reflect the complex and more accurate picture.

\section{Poor patient outcomes or lack of prescriber knowledge?}

The Doctors Company article examined 272 claims between 2007 and 2015 in which opioids resulted in patient harm. ${ }^{2}$ The author cited that poor patient outcomes related to opioids are a common cause of litigation, with contributing factors including the following: 
- Inappropriate selection and management of therapy.

- Errors in patient monitoring.

- Inadequate patient assessment for risks and contraindications to opioids.

- Failure in communication among providers.

- Insufficient documentation and/or support for clinical decision-making.

- Failure to take psychiatric and/or abuse history.

Perhaps the poor patient outcomes related to opioids are due to lack of prescriber education. ${ }^{18,19}$ Few medical and pharmacy schools offer adequate training in pain management and addiction. ${ }^{18,19}$

\section{Two wrongs do not make a right}

It is apparently convenient for critics of opioid analgesics to point fingers at politicians, industry, prescribers, and pharmacies as the culprits responsible for the opioid crisis. Policy makers, the media, and opiophobes continue to blame the pharmaceutical companies because they did not explicitly state the risks associated with opioids. It is curious that the government allows continued sales and advertisements by the tobacco industry when it clearly has a plethora of evidence that the risks far exceed the benefits, and that unlike opioids, there are no therapeutic benefits to smoking tobacco. This idea that it is acceptable to cite misleading, false, or over/ understated data, statistics, and facts must change. In his efforts to sound an already deafening alarm, Dr. Marcus has done just this. The fact that our own government cites fake medical literature negatively impacts the credibility of the medical and scientific establishments. Alternative facts ultimately lead to distrust not only in our patients but also among overly stressed health care providers who have the courage to continue to treat patients with pain.

Dr. Marcus works for an insurance company, yet nowhere does he note such as a blatant conflict of interest. Much has been written about the role of the insurance industry in the etiology and perpetuation of the opioid crisis. For example, it has been noted that the insurance industry's decision to stop providing coverage for interdisciplinary pain care, which had historically involved tapering patients down from and even off their opioids, played a dramatic role in the development of the opioid crisis. ${ }^{20}$ The temporal contiguity between the insurance industry "just saying no" to interdisciplinary care and the rise of opioid diversion and abuse has not escaped notice. ${ }^{21,22}$

Additionally, the insurance industry's failure to pay for more expensive but effective abuse deterrent formulations of opioids has certainly contributed to the figures that
Dr. Marcus recklessly cites. ${ }^{23}$ The Doctors Company was developed to allegedly protect the interests of physicians. In the present climate of increasing medical malpractice with opioid prescribing recently identified as the leading cause of medication malpractice claims, Dr. Marcus's inaccurate and irresponsible presentation of so-called facts can serve only to exacerbate the "chilling effect" on physicians already fearful of prescribing. ${ }^{24,25}$ While this sort of approach may promote the financial well-being of the Doctors Company, Dr. Marcus should be aware that he is not doing any favors to already marginalized chronic pain patients - as naive physicians may buy into the hyperbole and rhetoric that he has propagated, resulting in more opiophobia, oligoanalgesia, and needless suffering.

\section{Acknowledgments}

This article is the sole work of the authors; stated opinions or assertions do not reflect the opinions of employers or employee affiliates listed. The article was not prepared as part of the authors' duties as federal employees.

\section{Disclosure}

Dr Schatman would like to disclose that he is a consultant for Kaleo Pharma. Dr Fudin discloses the following: AcelRx Pharmaceuticals (Advisory Board), Astra Zeneca (Speakers Bureau), Daiichi Sankyo (Advisory Board, Speakers Bureau), GlaxoSmithKline (GSK) (Advisory Board), Quest Diagnostics (Advisory Board), Remitigate, LLC (Owner), Scilex Pharmaceuticals (Advisory Board), Bridge Therapeutics (Advisory Board), Firstox Laboratories (Consultant). The authors report no other conflicts of interest in this work.

\section{References}

1. History. The Doctors Company. Available from: https://www.thedoctors.com/about-the-doctors-company/the-doctors-company-history/. Accessed April 14, 2018.

2. Marcus H. Prescribing Opioids Safely. The Doctors Company. Available from: https://www.thedoctors.com/the-doctors-advocate/secondquarter-2017/prescribing-opioids-safely/. 2017. Accessed April 14, 2018.

3. Zinsser W. On Writing Well: The Classic Guide to Writing Nonfiction. New York: Harper-Collins Publishers, Inc.; 1976.

4. UNODC. World Drug Report 2011. The Opium/heroin market. (United Nations Publications, Sales No. E.11.XI.10). Available from: https:// www.unodc.org/documents/data-and-analysis/WDR2011/World_Drug Report_2011_ebook.pdf. Accessed April 14, 2018.

5. Manchikanti L, Fellows B, Ailinani H, Pampati V. Therapeutic use, abuse, and nonmedical use of opioids: a ten-year perspective. Pain Physician. 2010;13(5):401-435.

6. Donovan KJ, Fudin J. How changing hydrocodone scheduling will affect pain management. Pract Pain Manage. 2013;13(5):69-74.

7. Raouf M, Fudin J [webpage on the Internet]. Alternative Opioid Facts and the New Banana Republic. 2018. Available from: http://paindr.com/ alternative-opioid-facts-and-the-new-banana-republic/. Accessed April $10,2018$. 
8. Guy GP Jr, Zhang K, Bohm MK, et al. Vital signs: changes in opioid prescribing in the United States, 2006-2015. MMWR Morb Mortal Wkly Rep. 2017;66:697-704.

9. Centers for Disease Control and Prevention. Annual Surveillance Report of Drug-Related Risks and Outcomes - United States, 2017. Surveillance Special Report 1. Centers for Disease Control and Prevention, U.S. Department of Health and Human Services; 2017. Available from: https://www.cdc.gov/drugoverdose/pdf/pubs/2017-cdc-drugsurveillance-report.pdf. Accessed April 14, 2018.

10. Mojtabai R. National trends in long-term use of prescription opioids. Pharmacoepidemiol Drug Saf. 2018;27(5):526-534.

11. Institute of Medicine Report from the Committee on Advancing Pain Research, Care, and Education [webpage on the Internet]. Relieving Pain in America, A Blueprint for Transforming Prevention, Care, Education and Research. The National Academies Press; 2011. Available from: http://books.nap.edu/openbook.php?record_id=13172\&page=1 . Accessed April 14, 2018.

12. Kennedy-Hendricks A, Gielen A, McDonald E, McGinty EE, Shields W, Barry CL. Medical sharing, storage, and disposal practices for opioid medications among US adults. JAMA Intern Med. 2016;176(7):1027-1029.

13. Schatman ME, Ziegler SJ. Pain management, prescription opioid mortality, and the CDC: is the devil in the data? J Pain Res. 2017;10: 2489-2495.

14. Bowden J [webpage on the Internet]. Sessions: DEA to Target Pharmacies, Prescribers in Crackdown. 2018. Available from: http://thehill.com/ homenews/administration/371412-sessions-dea-to-target-pharmaciesprescribers-in-crackdown? Accessed January 30, 2018.

15. Somerville NJ, O'Donnell J, Gladden RM, et al. Characteristics of fentanyl overdose - Massachusetts, 2014-2016. MMWR Morb Mortal Wkly Rep. 2017;66(14):382-386.
16. Dasgupta N, Funk MJ, Proescholdbell S, Hirsch A, Ribisl KM, Marshall S. Cohort study of the impact of high-dose opioid analgesics on overdose mortality. Pain Med. 2016;17(1):85-98.

17. Hannah HA, Arambula K, Ereman R, Harris D, Torres A, Willis M. Using local toxicology data for drug overdose mortality surveillance. J Public Health Inform. 2017;9(1):e143.

18. Volkow ND, Mclellan AT. Opioid Abuse in chronic pain - misconceptions and mitigation strategies. NEngl J Med. 2016;374(13):1253-1263.

19. Loeser JD, Schatman ME. Chronic pain management in medical education: a disastrous omission. Postgrad Med. 2017;129(3):332-335.

20. Schatman ME. The role of the health insurance industry in perpetuating suboptimal pain management: ethical implications. Pain Med. 2011;12:415-426.

21. Schatman ME. The demise of interdisciplinary chronic pain management and its relationship to the scourge of prescription opioid diversion and abuse. In: Peppin J, Coleman J, Dineen KK, Ruggles A, editors. Pain and Prescription Drug Diversion: Healthcare, Law Enforcement, and Policy Perspectives. New York: Oxford University Press; 2018.

22. Pain and Prescription Drug Diversion: Healthcare, Law Enforcement, and Policy Perspectives. New York: Oxford University Press; 2018.

23. Schatman ME, Webster LR. The health insurance industry: perpetuating the opioid crisis through policies of cost-containment and profitability. J Pain Res. 2015;8:153-158.

24. Hanscom R, Small M, Lambrecht A [webpage on the Internet]. A Dose of Insight: A Data-Driven Review of the State of Medication-Related Errors \& Liability in American Healthcare. Coverys; 2018. Available from: https://coverys.com/PDFs/Coverys_White_Paper-A_Dose_of_Insight. aspx. Accessed April 14, 2018.

25. Ruan X, Luo JJ. Frustrated patients and fearful physicians. J Gen Intern Med. 2017;32(9):963.

Dove Medical Press encourages responsible, free and frank academic debate. The content of the Journal of Pain Research 'Editorial' section does not necessarily represent the views of Dove Medical Press, its officers, agents, employees, related entities or the Journal of Pain Research editors. While all reasonable steps have been taken to confirm the content of each Editorial, Dove Medical Press accepts no liability in respect of the content of any Editorial, nor is it responsible for the content and accuracy of any Editorial.

\section{Journal of Pain Research}

\section{Publish your work in this journal}

The Journal of Pain Research is an international, peer reviewed, open access, online journal that welcomes laboratory and clinical findings in the fields of pain research and the prevention and management of pain. Original research, reviews, symposium reports, hypothesis formation and commentaries are all considered for publication.

\section{Dovepress}

The manuscript management system is completely online and includes a very quick and fair peer-review system, which is all easy to use. Visit http://www.dovepress.com/testimonials.php to read real quotes from published authors. 